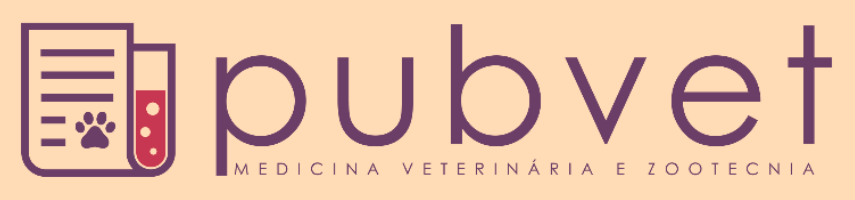

https://doi.org/10.31533/pubvet.v13n4a301.1-9

\title{
Produção de gramíneas forrageiras irrigadas com água de diferentes condutividades elétricas no semiárido do Piauí
}

\author{
Francisco José de Seixas Santos ${ }^{1^{*} \emptyset}$, Braz Henrique Nunes Rodrigues ${ }^{2} \bullet$, João Avelar \\ Magalhães $^{3}$, Newton de Lucena $\operatorname{Costa}^{4} \theta$ \\ ${ }^{1}$ Eng. Agron., D. Sc., Pesquisador da Embrapa Meio-Norte, Parnaíba, PI. \\ ${ }^{2}$ Eng. Agrícola., D. Sc., Pesquisador da Embrapa Meio-Norte, Parnaíba, PI. \\ ${ }^{3}$ Med. Veterinário, D. Sc., Pesquisador da Embrapa Meio-Norte, Parnaíba, PI. \\ ${ }^{4}$ Eng. Agr., D.Sc., Pesquisador da Embrapa Roraima, Boa Vista, RR. \\ *Autor para correspondência, E-mail: francisco.seixas@embrapa.br
}

\begin{abstract}
Resumo. O objetivo do trabalho foi avaliar a produção de forragem do sorgo (Sorghum vulgare), do capim-elefante (Pennisetum purpureum) e do capim-canarana (Echinochloa pyramidalis) na região semiárida do norte do Piauí utilizando água de irrigação de diferentes qualidades quanto à condutividade elétrica (CE). Nas regiões áridas e semiáridas as concentrações de sais podem atingir valores elevados, prejudicando o solo e as plantas. No caso da região semiárida do Nordeste brasileiro a água utilizada na irrigação apresenta, em grande parte, alto teor de sais, tanto em poços e como em açudes de pequeno e médio porte. Estudos voltados para seleção de espécies de gramíneas adaptadas e/ou tolerantes à salinidade via água devem ser incentivados, permitindo a utilização de águas de qualidade marginal na produção de alimentação animal e liberando a água doce para abastecimento humano e animal. $\mathrm{O}$ delineamento experimental foi blocos casualizados em esquema de parcelas subdivididas com quatro repetições, onde as águas de irrigação com diferentes condutividades elétricas constituíram as parcelas principais e as gramíneas forrageiras as parcelas subdivididas. Os tratamentos consistiram de 4 níveis de salinidade da água (S1, $\mathrm{S} 2, \mathrm{~S} 3$ e S4) correspondendo às $\mathrm{CE}$ de 0,$5 ; 1,5 ; 2,0$ e $2,5 \mathrm{dS} \mathrm{m}^{-1}$. Foram determinados a produção de matéria seca (PMS), os teores de proteína bruta (PB), de fibra em detergente neutro (FDN) e de fibra em detergente ácido (FDA). Os componentes de produção de biomassa forrageira, em termos de quantidade e qualidade, do sorgo e do capim-elefante não foram afetados pela irrigação com água com condutividade elétrica de até $2,5 \mathrm{dS} \mathrm{m}^{-1}$ nas condições edafoclimáticas do semiárido do norte do Piauí.
\end{abstract}

Palavras-chave: Produção de forragem, recursos hídricos, salinidade

\section{Productivity of forage grasses irrigated with water of different electrical conductivities in the semi-arid region of the north of Piaui}

Abstract: The objective of this work was to evaluate the forage production of sorghum
(Sorghum vulgare), elephant-grass (Pennisetum purpureum) and canarian grass
(Echinochloa pyramidalis) in the semi-arid region of north Piauí using irrigation water of
different qualities electrical conductivity (EC). In the arid and semi-arid regions the
concentrations of salts can reach high values, damaging the soil and the plants. In the case of
the semi-arid region of the Brazilian Northeast, the water used for irrigation is largely high
in salts, as in wells and small and medium-sized dams. Studies aimed at selecting species of
grasses adapted and / or tolerant to salinity via water should be encouraged, allowing the use
of waters of marginal quality in the production of animal feed and releasing fresh water for
human and animal supply. The experimental design was randomized blocks in a subdivided 
plots scheme with four replications, where the irrigation waters with different electrical conductivities (EC) constituted the main plots and the forage grasses subdivided plots. The treatments consisted of 4 levels of water salinity (S1, S2, S3 and S4) corresponding to EC of $0.5 ; 1.5 ; 2.0$ and $2.5 \mathrm{dS} \mathrm{m}^{-1}$. Dry matter production (DMP), crude protein (CP), neutral detergent fiber (NDF) and acid detergent fiber (ADF) were determined. The components of forage biomass production, in terms of quantity and quality, of sorghum and elephant-grass were not affected by irrigation with water with electrical conductivity of up to $2.5 \mathrm{dSm}^{-1}$ in the soil and climatic conditions of the semi-arid north of Piauí.

Keywords: Forage production, water resources, salinity

\title{
Producción de gramíneas forrajeras irrigadas con agua de diferentes conductividades eléctricas en el semiárido de Piauí
}

\begin{abstract}
Resumen: El objetivo del trabajo fue evaluar la producción de forraje del sorgo (Sorghum vulgare), del pasto-elefante (Pennisetum purpureum) y del capim-canarana (Echinochloa pyramidalis) en la región semiárida del norte de Piauí utilizando agua de riego de diferentes calidades en cuanto a conductividad eléctrica (CE). En las regiones áridas y semiáridas las concentraciones de sales pueden alcanzar valores elevados, perjudicando el suelo y las plantas. En el caso de la región semiárida del Nordeste brasileño el agua utilizada en la irrigación presenta, en gran parte, alto contenido de sales, tanto en pozos y como en azudes de pequeño y mediano porte. Los estudios orientados a la selección de especies de gramíneas adaptadas y / o tolerantes a la salinidad por agua deben ser incentivados, permitiendo la utilización de aguas de calidad marginal en la producción de alimentación animal y liberando el agua dulce para abastecimiento humano y animal. El diseño experimental fue bloques casualizados en esquema de parcelas subdivididas con cuatro repeticiones, donde las aguas de riego con diferentes conductividades eléctricas (CE) constituyeron las parcelas principales y las gramíneas forrajeras las parcelas subdivididas. Los tratamientos consistieron de 4 niveles de salinidad del agua (S1, S2, S3 y S4) correspondiendo a las CE de 0,$5 ; 1,5 ; 2,0$ y $2,5 \mathrm{dS} \mathrm{m}^{-1}$. Se determinaron la producción de materia seca (PMS), los contenidos de proteína cruda (PC), de fibra en detergente neutro (FDN) y de fibra en detergente ácido (FDA). Los componentes de producción de biomasa forrajera, en términos de cantidad y calidad, del sorgo y del pasto elefante no fueron afectados por la irrigación con agua con conductividad eléctrica de hasta $2,5 \mathrm{dS} \mathrm{m}^{-1}$ en las condiciones edafoclimáticas del semiárido del norte de Piauí.
\end{abstract}

Palabras clave: Producción de forraje, recursos hídricos, salinidad

\section{Introdução}

Nas regiões áridas e semiáridas as concentrações de sais podem atingir valores elevados com prejuízos para o solo e as plantas. Isso ocorre devido às características climáticas dessas regiões, com elevadas taxas de evaporação e transpiração além da baixa precipitação, possibilitando a ascensão de sais para a superfície do solo (Medeiros et al., 2011). A irrigação, mesmo com água de baixa salinidade, adiciona sais aos solos que provocam o incremento salino e perdas de extensas áreas produtivas (Cavalcante et al., 2016). As águas de uma região naturalmente contêm menos sais antes do desenvolvimento de um projeto de irrigação (Holanda et al., 2016).

De acordo com Ribeiro et al. (2016) na região Nordeste a pressão econômica pela produção de alimentos, devido ao crescimento da população, tem resultado no aumento da área de solos degradados por salinidade e sodicidade, em virtude da expansão das áreas irrigadas em terras marginais, do uso de águas salinas na irrigação, do manejo inadequado da água e do solo, e da ausência de drenagem, com grandes prejuízos para a economia regional.

Na região semiárida do Nordeste brasileiro a água utilizada na irrigação apresenta, em grande parte, alto teor de sais, como nos açudes de pequeno e médio porte (Araújo, 2011) e poços, sendo que na região existem por volta de 120.000 poços tubulares captando água do cristalino do Polígono das Secas (Feitosa 
\& Feitosa, 2011). Os poços tubulares e cacimbões são, predominantemente, a fonte abastecedora das pequenas propriedades. Desta forma, numa região onde a escassez de forragem, devido à falta de chuvas, tem diminuído consideravelmente os rebanhos, estudos voltados para seleção de espécies de gramíneas adaptadas e/ou tolerantes à salinidade via água devem ser incentivados, permitindo a utilização de águas de qualidade marginal na produção de alimentos para o consumo animal e liberando a água doce para abastecimento humano e animal.

Os principais fatores que causam limitações no crescimento de plantas cultivadas em ambientes salinos, em termos gerais, são caracterizados como: estresse hídrico, estresse iônico específico ou toxicidade e estresse provocado pelo desequilíbrio iônico ou deficiência nutricional induzida, ou, ainda, a combinação destes fatores (Greenway \& Munns, 1980; Levitt, 1972).

Em seu estudo Morais Neto et al. (2012) apontaram que o capim-canarana pode ser mais uma opção de cultivo em ambientes afetados por sais no Nordeste. Pesquisas conduzidas em Pernambuco indicaram que capim-elefante e o sorgo podem ser tolerantes à salinidade do solo (Nunes Filho et al., 2007). Vale \& Azevedo (2013) também avaliaram a produtividade e a qualidade do capim-elefante e do sorgo em solo irrigado com água de lençol freático e de rejeito de dessalinizador. Segundo Soares Filho et al. (2016) são necessários trabalhos que estudem a avaliação de espécies, ou de genótipos de uma mesma espécie, quanto à sua tolerância à salinidade em condições de campo, sendo que a metodologia pode variar de acordo com as condições climáticas da região, tipo de solo, nível de salinidade do solo e da água.

O objetivo do trabalho foi avaliar a produção de forragem do sorgo, do capim-elefante e do capimcanarana na região da caatinga do norte do Piauí utilizando água de irrigação de diferentes qualidades quanto à condutividade elétrica (CE).

\section{Material e métodos}

O trabalho foi conduzido na Unidade de Execução de Pesquisa de Parnaíba, pertencente à Embrapa

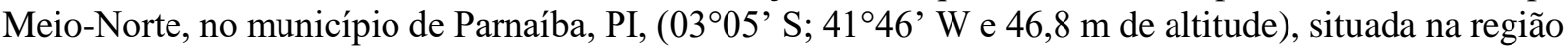
de abrangência do semiárido (SUDENE, 2017).

O clima da região, de acordo com a classificação climática de Thornthwaite \& Mather é C1dA'a', caracterizado como sub-úmido seco, megatérmico, com pequeno excedente hídrico e uma concentração de $29,7 \%$ da evapotranspiração potencial no trimestre outubro, novembro e dezembro (Köppen \& Geiger, 1928). A normal climatológica de precipitação total anual no período de 1978 a 2014 é de 1033,5 $\mathrm{mm}$ (Bastos et al., 2016). No ano de 2017 o total de precipitação foi de $880,6 \mathrm{~mm}$, sem nenhum registro nos meses de setembro a dezembro.

O solo da área experimental é da classe Latossolo Amarelo distrófico, textura média, fase caatinga litorânea e relevo plano e suave ondulado (Melo et al., 2004; EMBRAPA, 2006). No início do experimento o solo apresentou as seguintes características químicas: $\mathrm{MO}=13,89 \mathrm{~g} / \mathrm{kg} ; \mathrm{pH}\left(\mathrm{H}_{2} \mathrm{O}\right)=$ 5,$47 ; \mathrm{P}=9,57 \mathrm{mg} / \mathrm{dm}^{3} ; \mathrm{N}=0,60 \mathrm{~g} / \mathrm{kg} ; \mathrm{K}=0,19 \mathrm{cmol}_{\mathrm{c}} / \mathrm{dm}^{3} ; \mathrm{Ca}=3,25 \mathrm{cmol}_{\mathcal{c}} / \mathrm{dm}^{3} ; \mathrm{Mg}=0,55 \mathrm{cmol}_{\mathrm{c}} / \mathrm{dm}^{3} ;$ $\mathrm{Na}=0,15 \mathrm{cmol}_{\mathrm{c}} / \mathrm{dm}^{3} ; \mathrm{Al}=0,08 \mathrm{cmol}_{\mathrm{c}} / \mathrm{dm}^{3} ; \mathrm{H}+\mathrm{Al}=2,93 \mathrm{cmol}_{\mathrm{c}} / \mathrm{dm}^{3} ; \mathrm{CTC}=6,91 \mathrm{cmol}_{c} / \mathrm{dm}^{3}$.

Foram testadas três gramíneas forrageiras: capim-canarana (Echinochloa pyramidalis), capimelefante (Pennisetum purpureum) e sorgo (Sorghum vulgare). O delineamento experimental foi blocos casualizados em esquema de parcelas subdivididas com quatro repetições, onde as águas de irrigação com diferentes condutividades elétricas (CE) constituíram as parcelas principais e as gramíneas forrageiras as sub-parcelas. Cada bloco foi constituído de doze parcelas $\left(12 \mathrm{~m}^{2}\right.$ cada) com área total de $144 \mathrm{~m}^{2}$. O espaçamento entre blocos foi de $12 \mathrm{~m}$ visando evitar a interferência dos jatos de água de um tratamento em outro.

Os tratamentos consistiram de 4 níveis de salinidade da água (S1, S2, S3 e S4) correspondendo às $\mathrm{CE}$ de 0,$5 ; 1,5 ; 2,0$ e $2,5 \mathrm{dS} \mathrm{m}^{-1}$. A partir da água disponível na UEP-Parnaíba (CE $\left.0,5 \mathrm{dS} \mathrm{m}^{-1}\right)$ foram formuladas as outras diferentes salinidades com adição de $\mathrm{NaCl}, \mathrm{CaCl}_{2} \cdot 2 \mathrm{H}_{2} \mathrm{O}$ e $\mathrm{MgCl}_{2} \cdot 6 \mathrm{H}_{2} \mathrm{O}$, de forma a se obter a CE considerando a proporção equivalente 7:2:1 para $\mathrm{Na}: \mathrm{Ca}: \mathrm{Mg}$. A preparação das águas foi realizada em reservatórios de concreto $(13.500 \mathrm{~L})$ específicos para cada condutividade. Após cada formulação foram realizadas análises das águas para confirmação da CE. 
O capim-elefante e o capim-canarana foram plantados por estacas no dia 11/07/2017 e o corte de uniformização para início dos tratamentos do primeiro ciclo de cultivo foi realizado no dia 18/08/2017, data em que foi semeado o sorgo em bandejas para posterior transplantio (31/08/2017) visando à padronização do número de plantas nas parcelas. O espaçamento de plantio foi $0,5 \mathrm{~m}$ x $0,2 \mathrm{~m}$ e a adubação de fundação constou da aplicação de $40 \mathrm{~kg} \mathrm{P}_{2} \mathrm{O}_{5} / \mathrm{ha}$, na forma de superfosfato simples, para todas as gramíneas. A adubação de cobertura foi realizada utilizando $300 \mathrm{~kg} \mathrm{~N} / \mathrm{ha} / \mathrm{ano}$ (na forma de ureia) e 100 $\mathrm{kg} \mathrm{K}_{2} \mathrm{O} / \mathrm{ha} / \mathrm{ano}$ (na forma de cloreto de potássio), uma única vez no caso do capim-canarana e do capimelefante, após cada corte, e fracionada em três vezes no sorgo após a germinação/rebrota. Foram realizados dois cortes com intervalo de 60 dias.

Para aplicação da água de irrigação foi utilizado um sistema de aspersão convencional fixo, por meio de aspersores setoriais de vazão de $0,51 \mathrm{~m}^{3} \cdot \mathrm{h}^{-1}$, pressão de serviço de $250 \mathrm{kPa}$ e espaçados de $10 \mathrm{~m} \mathrm{x}$ $10 \mathrm{~m}$. O manejo da irrigação foi baseado em $100 \%$ da evapotranspiração de referência (ETo) determinada pelo método de Penman Monteith.

$\mathrm{Na}$ ocasião dos cortes a coleta de biomassa foi realizada nas áreas úteis das parcelas e levadas imediatamente à sala de preparo para pesagem do material verde e retirada de sub-amostras. Em seguida foram submetidas à secagem em estufa com circulação forçada de ar a $65^{\circ} \mathrm{C}$ até atingirem peso constante, para a determinação da estimativa da produção de matéria seca (MS). No Laboratório de Análise e Processamento de Alimentos da Embrapa Meio-Norte/UEP de Parnaíba foram determinados os teores de proteína bruta (PB), pelo método de Kjeldahl, fibra em detergente neutro (FDN) e fibra em detergente ácido (FDA) de acordo com a metodologia preconizada por AOAC (2005). A digestão para obtenção da FDN e FDA foi realizada em aparelho de digestão de fibra. Os dados foram analisados utilizando-se o pacote estatístico Infostat (Di Rienzo et al., 2008).

\section{Resultados e discussão}

Em cada ciclo de cultivo foi aplicado uma lâmina de água total média de 401,34 $\mathrm{mm}$. A partir da análise de variância não foi possível detectar interação entre a condutividade elétrica (CE) e a produção de matéria seca (MS) das gramíneas estudadas. Entretanto, a análise dos efeitos isoladamente apresentou diferença entre as gramíneas (Tabela 1). A produção de MS não foi influenciada pelos tratamentos de CE. Contudo, é possível observar uma diminuição contínua da MS do tratamento com menor condutividade $\left(0,5 \mathrm{dS} \mathrm{m}^{-1}\right)$ para a de maior $\left(2,5 \mathrm{dS} \mathrm{m}^{-1}\right)$. Analisando-se isoladamente as espécies, o sorgo apresentou maior produção de MS $\left(5.650,0 \mathrm{~kg} \mathrm{ha}^{-1}\right)$, não diferindo da produção do capim-elefante $\left(4.859,0 \mathrm{~kg} \mathrm{ha}^{-1}\right)$ e $164,9 \%$ superior à produção do capim-canarana.

Tabela 1. Produção de matéria de seca (MS) de gramíneas forrageiras irrigadas com água de diferentes valores de condutividade elétrica (CE). Parnaíba-PI

\begin{tabular}{|c|c|c|c|}
\hline Condutividade elétrica $\left(\mathrm{dS} \mathrm{m}^{-1}\right)$ & Produção de MS $\left(\mathrm{kg} \mathrm{ha}^{-1}\right)$ & Gramíneas & Produção de MS $\left(\mathrm{kg} \mathrm{ha}^{-1}\right)$ \\
\hline $0,5(\mathrm{~S} 1)$ & $4.611,53^{\mathrm{A}}$ & Capim-canarana & $2.133,18^{\mathrm{B}}$ \\
\hline $1,5(\mathrm{~S} 2)$ & $4.152,69^{\mathrm{A}}$ & Capim-elefante & $4.859,00^{\mathrm{A}}$ \\
\hline $2,0(\mathrm{~S} 3)$ & $4.296,70^{\mathrm{A}}$ & Sorgo & $5.650,03^{\mathrm{A}}$ \\
\hline $2,5(\mathrm{~S} 4)$ & $3.795,35^{\mathrm{A}}$ & & \\
\hline $\mathrm{DMS}^{1}$ & $1.411,77$ & $\mathrm{DMS}^{1}$ & $1.109,62$ \\
\hline
\end{tabular}

Nas colunas, médias seguidas da mesma letra não diferem estatisticamente entre si ao nível de 5\% pelo teste de Tukey. ${ }^{1}$ Diferença Mínima Significativa

Para o sorgo a produção de MS utilizando água com CE 2,5 dS m${ }^{-1}$ foi de 5.340,0 $\mathrm{kg} \mathrm{ha}^{-1}$, valor semelhante ao obtido por Silva et al. (2014) utilizando água com CE de 2,75 dS m${ }^{-1}\left(5.120 \mathrm{~kg} \mathrm{ha}^{-1}\right) \mathrm{em}$ solo Argissolo Vermelho-Amarelo Eutrófico. De acordo com Coelho et al. (2017), em estudo com dez genótipos de sorgo forrageiro, a MS da parte aérea apresentou redução linear com aumento da salinidade $\left(\hat{y}=-6,86 x+105,7 ; R^{2}=0,96\right)$. Ademais, foi observada a redução da quantidade de macronutrientes acumulada em folhas, colmos e raízes de sorgo forrageiro, estando diretamente relacionada com as perdas de MS.

A MS do capim-elefante e do capim-canarana foram ajustadas quadraticamente aos níveis de CE e explicadas, respectivamente, pelas equações $\mathrm{y}=5104,6+1250,8 \mathrm{x}-714,71 \mathrm{x}^{2}\left(\mathrm{R}^{2}=0,97\right)$ e $\mathrm{y}=1076,6$ 
$+1427,3 \mathrm{x}-396,2 \mathrm{x}^{2}\left(\mathrm{R}^{2}=0,92\right)$. A produção ajustada de matéria seca (MS) do capim-elefante com a máxima condutividade elétrica utilizada $\left(2,5 \mathrm{dS} \mathrm{m}^{-1}\right)$ foi de $3.764,7 \mathrm{~kg} \mathrm{ha}^{-1}$, superior às obtidas por Vale \& Azevedo (2013) para o capim-elefante verde (corte aos 60 dias) irrigado com água do lençol freático $\left(2,89 \mathrm{dS} \mathrm{m}^{-1}\right) \mathrm{e}$ do rejeito do dessalinizador $\left(3,69 \mathrm{dS} \mathrm{m}^{-1}\right)$, respectivamente $3.500 \mathrm{~kg} \mathrm{ha}^{-1} \mathrm{e} 2.600 \mathrm{~kg} \mathrm{ha}^{-1}$. Dantas et al. (2006) trabalhando com dois níveis de salinidade $\left(0,69 \mathrm{dS} \mathrm{m}^{-1}\right.$ e $\left.15 \mathrm{dS} \mathrm{m}^{-1}\right)$ constataram diminuição da produção de biomassa seca, em todos os clones de capim-elefante, com redução que variou de 42 a $70 \%$. Tendências semelhantes foram reportadas por Sangakkara (1994) após trabalhar com Brachiaria mutica, Paspalum dilatatum e Megathyrsus maximus recebendo níveis de $0,5 \mathrm{mS} / \mathrm{cm}$ a $5,9 \mathrm{mS} / \mathrm{cm}$.

A gramínea que apresentou menor produção média de MS foi o capim-canarana $\left(2.133,2 \mathrm{~kg} \mathrm{ha}^{-1}\right)$ com a produção ajustada de MS para a condutividade elétrica de 2,5 dS m${ }^{-1}$ de 2168,60 kg ha ${ }^{-1}$. Morais Neto et al. (2012), trabalhando com vasos com capacidade para $8 \mathrm{~L}$ (contendo três plantas), solo Neossolo Quartzarênico textura arenosa, em casa de vegetação, constataram que a massa seca de forragem total foi influenciada pela salinidade, apresentando uma relação linear inversa $(y=9,002$ $0,312 \mathrm{x} ; \mathrm{R}^{2}=0,98 ; \mathrm{g}$ de $\mathrm{MS} / \mathrm{vaso}$ ) e que o capim-canarana pode ser irrigado com água de condutividade elétrica de até $2,0 \mathrm{dS} \mathrm{m}^{-1}$, sem que os seus componentes de biomassa sejam afetados. Chaves et al. (2018) avaliando área irrigada por inundação em solo Neossolo flúvico, condutividade elétrica do solo de $0,61 \mathrm{dS} \mathrm{m}^{-1}(0-20 \mathrm{~cm})$, determinaram que a massa seca de forragem total (MSFT) do capim-canarana aumentou com o avanço da idade de rebrotação, atingindo valores superiores a $5.000 \mathrm{~kg} \mathrm{ha}^{-1}$ aos 35 dias, de acordo com a equação MSFT $=1.031,6+139,78 x\left(R^{2}=0,9939\right)$.

Segundo Dias et al. (2016) a salinidade reduz a capacidade da planta em absorver água e, consequentemente, afeta a fotossíntese, sendo que o crescimento das plantas, geralmente, não é afetado até 2,0 dS m${ }^{-1}$, embora possam ser encontradas respostas diferentes entre espécies e cultivares. Para Lacerda et al. (2016) a salinidade limita o crescimento das plantas em decorrência dos efeitos osmóticos, tóxicos e nutricionais, e os resultados mais prováveis dos efeitos da salinidade na nutrição mineral podem ser a redução no crescimento e as alterações na qualidade do produto vegetal, que em plantas forrageiras se caracteriza acúmulo excessivo de sais.

$\mathrm{Na}$ análise de variância não foi detectada interação entre CE e gramíneas sobre os teores de proteína bruta (PB), bem como para seus efeitos isolados (Tabela 2). Os teores de PB não foram influenciados pelos valores de condutividade elétrica (CE) testados. Isoladamente, as espécies também apresentaram teores de PB semelhantes. Após trabalhar com níveis de salinidade até 5,0 dS m ${ }^{-1}$ (Santos et al., 2013; Silva et al., 2014) também não encontraram diferenças nos teores de PB do capim-marandu, milho e sorgo. Ressalta-se que os teores de PB aqui apresentados podem estar relacionados à idade da planta, pois as mais velhas podem apresentar menor teor proteico devido ao efeito da diluição, reduzindo de acordo com o desenvolvimento da cultura (Vale \& Azevedo, 2013). Contudo, os teores de PB estão acima do limite mínimo de 7\% recomendado para ruminantes (Minson, 2012).

Tabela 2. Teores de Proteína Bruta (PB) de gramíneas forrageiras irrigadas com água de diferentes valores de condutividade elétrica. Parnaíba-PI

\begin{tabular}{lclc}
\hline Condutividade elétrica $\left(\mathrm{dS} \mathrm{m}^{-1}\right)$ & PB $(\%)$ & Gramíneas & PB $(\%)$ \\
\hline $0,5(\mathrm{~S} 1)$ & $8,37 \mathrm{~A}$ & Capim-canarana & $8,41 \mathrm{~A}$ \\
$1,5(\mathrm{~S} 2)$ & $8,39 \mathrm{~A}$ & Capim-elefante & $8,53 \mathrm{~A}$ \\
$2,0(\mathrm{~S} 3)$ & $8,44 \mathrm{~A}$ & Sorgo & $8,60 \mathrm{~A}$ \\
$2,5(\mathrm{~S} 4)$ & $8,85 \mathrm{~A}$ & & \\
\hline DMS $^{1}$ & 1,02 & DMS $^{1}$ & 0,80
\end{tabular}

Nas colunas, médias seguidas da mesma letra não diferem estatisticamente entre si ao nível de 5\% pelo teste de Tukey.

${ }^{1}$ Diferença Mínima Significativa

Dentre as gramíneas, apenas o sorgo ajustou-se linearmente aos níveis de CE, explicado pela equação de regressão $\mathrm{y}=7,771+0,3931 \mathrm{x}\left(\mathrm{R}^{2}=0,75\right)$. Este resultado diferencia-se do obtido por Vieira et al. (2005) que encontraram efeitos negativos dos níveis de salinidade $\left(0,90,2,60,4,20\right.$ e 5,80 dS m$\left.{ }^{-1}\right)$ sobre os teores de PB do sorgo; porém, com significância apenas no nível mais elevado de sais. Possivelmente, no presente experimento, os níveis testados de condutividade elétrica tenderam a melhorar o valor 
nutritivo da planta, devido à redução da disponibilidade de água no solo, promovendo assim, atraso na maturidade e no desenvolvimento do colmo, com a manutenção de uma boa relação folha/colmo.

$\mathrm{Na}$ análise de variância também não foi detectada interação entre $\mathrm{CE}$ e as espécies de gramíneas testadas sobre os teores de fibra em detergente neutro (FDN) (Tabela 3). Contudo, foram detectados efeitos isolados dos tratamentos para esta variável. O maior teor de FDN $(64,9 \%)$ foi observado quando se aplicou $1,5 \mathrm{dS} \mathrm{m}^{-1}$, que foi superior ao maior nível de condutividade elétrica $\left(2,5 \mathrm{dS} \mathrm{m}^{-1}\right)$ que apresentou o menor teor $(61,8 \%)$. Os níveis de $0,5 \mathrm{dS} \mathrm{m}^{-1}$ e $2,0 \mathrm{dS} \mathrm{m}^{-1}$ tiveram comportamentos semelhantes aos níveis $1,5 \mathrm{dS} \mathrm{m}^{-1}$ e $2,5 \mathrm{dS} \mathrm{m}^{-1}$. Isoladamente, o capim-elefante apresentou os maiores teores de FDN $(68,4 \%)$, seguido do capim-canarana $(63,0 \%)$ e do sorgo $(58,8 \%)$. Ressalta-se que estão dentro dos limites encontrados entre a maioria das gramíneas tropicais cortadas aos 60 dias de rebrota.

Tabela 3. Teores de fibra em detergente neutro (FDN) de gramíneas forrageiras irrigadas com água de diferentes valores de condutividade elétrica. Parnaíba-PI.

\begin{tabular}{lccc}
\hline Condutividade elétrica $\left(\mathrm{dS} \mathrm{m}^{-1}\right)$ & FDN $(\%)$ & Gramíneas & FDN $(\%)$ \\
\hline $0,5(\mathrm{~S} 1)$ & $63,84 \mathrm{AB}$ & Capim-canarana & $63,02 \mathrm{~B}$ \\
$1,5(\mathrm{~S} 2)$ & $64,95 \mathrm{~A}$ & Capim-elefante & $68,37 \mathrm{~A}$ \\
$2,0(\mathrm{~S} 3)$ & $63,21 \mathrm{BA}$ & Sorgo & $58,84 \mathrm{C}$ \\
$2,5(\mathrm{~S} 4)$ & $61,85 \mathrm{~B}$ & & \\
\hline DMS $^{1}$ & 2,36 & DMS $^{1}$ & 1,86 \\
\hline
\end{tabular}

Nas colunas, médias seguidas da mesma letra não diferem estatisticamente entre si ao nível de 5\% pelo teste de Tukey.

${ }^{1}$ Diferença Mínima Significativa

Considerando isoladamente as gramíneas, nas análises de regressão foi apontado efeito quadrático sobre os teores de FDN do capim-canarana $\left(\mathrm{y}=62,136+4,3039 \mathrm{x}-1,9791 \mathrm{x}^{2} ; \mathrm{R}^{2}=0,88\right)$, do capimelefante $\left(y=66,836+3,8522 \mathrm{x}-1,4818 \mathrm{x}^{2} ; \mathrm{R}^{2}=0,85\right)$ e do sorgo $\left(\mathrm{y}=56,18+6,2068 \mathrm{x}-2,3282 \mathrm{x}^{2} ; \mathrm{R}^{2}=\right.$ 0,75), com valores estimados de FDNmax de 64,7\%; 69,3\% e 60,3\% e obtidos sob níveis de salinidade de 1,$1 ; 1,3$ e $1,3 \mathrm{dS} \mathrm{m}^{-1}$, respectivamente.

Em geral, estes resultados aqui reportados expõem evidências que os maiores volumes de sais reduzem o crescimento das plantas e, consequentemente, retarda a sua maturidade fisiológica, implicando em menores teores de FDN. Contudo, embora melhore o valor nutritivo, menores taxas de crescimento resultam em menores produtividades de forragem. Euclides et al. (1992) estudando diversas cultivares de Megathyrsus maximus, concluiu que valores de 55\% de FDN são raros. Valores superiores a 65\% são comuns em tecidos novos e teores entre 75 e $80 \%$ são encontrados em materiais de maturidade bastante avançada. Segundo Van Soest (1994), níveis superiores a 60\% de FDN na MS correlacionamse negativamente com o consumo de forragem.

$\mathrm{Na}$ análise de variância não foi detectada interação entre CE e gramíneas sobre os teores de fibra em detergente ácido (FDA) (Tabela 4). Isoladamente só foram observadas diferenças significativas entre as gramíneas para esta variável, cujos maiores teores foram apresentados pelo capim-elefante, seguido do capim-canarana e do sorgo. A determinação da FDA representa a quantidade de fibra que não é digerível, correspondendo à porcentagem de lignina e celulose presente na planta, cujo teor deve estar em torno de $30 \%$, pois estes níveis favorecem a digestibilidade do alimento.

Tabela 4. Teores de fibra em detergente ácido (FDA) de gramíneas forrageiras irrigadas com água salina com diferentes valores de condutividade elétrica. Parnaíba-PI.

\begin{tabular}{lccc}
\hline Condutividade elétrica $\left(\mathrm{dS} \mathrm{m}{ }^{-1}\right)$ & FDA $(\%)$ & Gramíneas & FDA (\%) \\
\hline $0,5(\mathrm{~S} 1)$ & $32,22 \mathrm{~A}$ & Capim-canarana & $32,17 \mathrm{~B}$ \\
$1,5(\mathrm{~S} 2)$ & $32,41 \mathrm{~A}$ & Capim-elefante & $34,85 \mathrm{~A}$ \\
$2,0(\mathrm{~S} 3)$ & $32,79 \mathrm{~A}$ & Sorgo & $28,63 \mathrm{C}$ \\
$2,5(\mathrm{~S} 4)$ & $30,12 \mathrm{~A}$ & & \\
\hline DMS $^{1}$ & 2,89 & DMS $^{1}$ & 2,27
\end{tabular}

Nas colunas, médias seguidas da mesma letra não diferem estatisticamente entre si ao nível de 5\% pelo teste de Tukey. ${ }^{1}$ Diferença Mínima Significativa. 
Isoladamente, os níveis de salinidade promoveram efeito quadrático $(\mathrm{y}=30,466+4,1722 \mathrm{x}-$ $\left.1,6818 \mathrm{x}^{2} ; \mathrm{R}^{2}=0,80\right)$ sobre os teores de FDA, cujo valor estimado de FDAmax $(33,1 \%)$ foi obtido com a aplicação de $1,2 \mathrm{dS} \mathrm{m}^{-1}$. Excetuando o capim-elefante, nas análises de regressão foi mostrado efeito quadrático sobre os teores de FDA do capim-canarana $\left(y=28,47+9,3159 x-3,579 x^{2} ; R^{2}=0,96\right)$, com FDAmax $(34,53 \%)$ obtido com a aplicação de $1,3 \mathrm{dS} \mathrm{m}^{-1}$. Para o sorgo o efeito foi linear e negativo (y $=30,446-1,1177 \mathrm{x})$. Após trabalhar com níveis de salinidade de $0,90 \mathrm{dS} \mathrm{m}^{-1}$ a 5,80 dS m $\mathrm{m}^{-1}$. Vieira et al. (2005) não encontraram feitos significativos sobre os teores de FDA do sorgo.

Os teores de FDA têm relação com os teores de lignina dos alimentos, que determinam a digestibilidade da fibra, pois quanto menor o teor de FDA, menor será o de lignina e, consequentemente, melhor a digestibilidade do alimento. Observou-se que os menores teores de FDA foram obtidos no tratamento com maiores teores de sais na água. $\mathrm{O}$ excesso de sais na água causa atraso na maturidade, no crescimento e desenvolvimento do caule, diminuindo o processo de lignificação.

\section{Conclusões}

Os componentes de produção de biomassa forrageira, em termos de quantidade e qualidade, do sorgo e do capim-elefante não foram afetados pela irrigação com água com condutividade elétrica de até 2,5 $\mathrm{dS} \mathrm{m}{ }^{-1}$ nas condições edafoclimáticas do semiárido do norte do Piauí.

\section{Referências bibliográficas}

AOAC. (2005). Association Official Analytical Chemist (2005) (Official Methods of Analysis (18th ed.) ed.). Gaitherburg, Maryland, USA: AOAC.

Araújo, J. C. (2011). Gestão das águas de pequenos açudes na região semi-árida. In S. S. Medeiros, H. R. Gueyi, C. O. Galvão \& V. P. S. Paz (Eds.), Recursos hídricos em regiões áridas e semiáridas. Campina Grande, Paraíba, Brasil: Instituto Nacional do Semiárido.

Bastos, E. A., Andrade Junior, A. S. \& Rodrigues, B. H. N. (2016). Boletim agrometeorológico de 2015 para o Município de Parnaíba, Piauí. Embrapa Meio-Norte, Teresina, Piauí, Brasil.

Cavalcante, L. F., Santos, R. V., Hernandez, F. F. F., Gheyi, H. R., Dias, T. J., Nunes, J. C. \& Lima, G. S. (2016). Recuperação de solos afetados por sais. In H. R. Gheyi, N. S. Dias, C. F. Lacerda \& E. Gomes Filho (Eds.), Manejo da salinidade na agricultura: Estudo básico e aplicados. Fortaleza, Ceará, Brasil.: INCTSal.

Chaves, D. R., Cândido, M. J. D., Furtado, R. N., Pompeu, R. C. F. F. \& Maranhão, T. D. (2018). Morfogênese de capim-canarana com duas frequências e duas intensidades de desfolhação. Archivos de Zootecnia, 67(259):396-402.

Coelho, D. S., Simões, W. L., Salviano, A. M., Souza, M. A. \& Santos, J. E. (2017). Acúmulo e distribuição de nutrientes em genótipos de sorgo forrageiro sob salinidade. Revista Brasileira de Milho e Sorgo, 16(2):178-192.

Dantas, J. A., Neto, E. B., Barreto, L. P. \& Santos, M. V. F. (2006). Efeito da salinidade sobre o crescimento e composição mineral de seis clones de Pennisetum. Revista Ciência Agronômica, 37(1):97-101.

Di Rienzo, J. A., Casanoves, F., Balzarini, M. G., Gonzalez, L., Tablada, M. \& Robledo, C. W. (2008). InfoStat, versión 2008, Grupo InfoStat, FCA. Córdoba, Argentina: Universidad Nacional de Córdoba.

Dias, N. S., Blanco, F. F., Souza, E. R., Ferreira, J. F. S., Sousa Neto, O. N. \& Queiroz, I. S. R. (2016). Efeitos dos sais na planta e tolerância das culturas à salinidade. In H. R. Gheyi, N. S. Dias, C. F. Lacerda \& E. Gomes Filho (Eds.), Manejo da salinidade na agricultura: Estudo básico e aplicados. Fortaleza, Ceará, Brasil: INCTSal.

EMBRAPA. (2006). Sistema brasileiro de classificação de solos (Vol. 412).

Euclides, V. P. B., Macedo, M. C. M. \& Oliveira, M. P. (1992). Avaliação de diferentes métodos de amostragem para estimar o valor nutritivo de forragens sob pastejo. Revista Brasileira de Zootecnia, 21(4):691-702. 
Feitosa, F. A. C. \& Feitosa, E. C. (2011). Realidade e perspectivas do uso racional de águas subterrâneas na região semiárida do Brasil. In S. S. Medeiros, H. R. Gueyi, C. O. Galvão \& V. P. S. Paz (Eds.), Recursos hídricos em regiões áridas e semiáridas. Campina Grande, Paraíba, Brasil: Instituto Nacional do Semiárido.

Greenway, H. \& Munns, R. (1980). Mechanisms of salt tolerance in nonhalophytes. Annual Review of Plant Physiology, 31(1):149-190.

Holanda, J. S., Amorim, J. R. A., Ferreira Neto, M., Holanda, A. C. \& Sá, F. V. S. (2016). Qualidade da água para irrigação. In H. R. Gheyi, N. Dias, C. F. Lacerda \& E. Gomes Filho (Eds.), Manejo da salinidade na agricultura: Estudo básico e aplicados. Fortaleza, Ceará, Brasil: INCTSal.

Köppen, W. \& Geiger, R. (1928). Klimate der Erde. Gotha: Verlag Justus Perthes. Wall-map $150 \mathrm{~cm} \times 200 \mathrm{~cm}$.

Lacerda, C. F., Costa, R. N. T., Bezerra, M. A., Neves, A. L. R., Sousa, G. G. \& Gheyi, H. R. (2016). Estratégias de manejo para uso de água salina na agricultura. In H. R. Gheyi, N. S. Dias, C. F. Lacerda \& E. Gomes Filho (Eds.), Manejo da salinidade na agricultura: Estudo básico e aplicados. Fortaleza, Ceará, Brasil: INCTSal.

Levitt, J. (1972). Response of plants to environmental stress. New York, USA.: Academic Press.

Medeiros, S. S., Gueyi, H. R., Galvão, C. O. \& Paz, V. P. S. (2011). Recursos hídricos em regiões áridas e semiáridas. Campina Grande, Paraíba, Brasil: Instituto Nacional do Semiárido.

Melo, F. B., Cavalcante, A. C., Andrade Júnior, A. S. \& Bastos, E. A. 2004. Levantamento detalhado dos solos da área da Embrapa Meio-Norte/UEP de Parnaíba. Embrapa Meio-Norte, Teresina, Piauí, Brasil.

Minson, D. (2012). Forage in ruminant nutrition (Vol. 1). New York: Academic Press.

Morais Neto, L. B., Carneiro, M. S. S., Lacerda, C. F., Costa, M. R. G. F., Fontenele, R. M. \& Feitosa, J. V. (2012). Effect of irrigation water salinity and cutting age on the components of biomass of Echinochloa pyramidalis. Revista Brasileira de Zootecnia, 41(3):550-556.

Nunes Filho, J., Lima e Sá, V. A., Sousa, A. R., Ferraz, L. G. B., Tabosa, J. N., Santos, V. F. \& Silva, A. B. (2007). Gramíneas forrageiras tropicais em solo slino-sódico, sob irrigação, no Vale do Rio Moxotó-Pernambuco. Pesquisa Agropecuária Pernambucana, 1419-24.

Ribeiro, M. R., Ribeiro Filho, M. R. \& Jacomine, P. K. T. (2016). Origem e classificação dos solos afetados por sais. In H. R. Gheyi, N. Dias, C. F. Lacerda \& E. Gomes Filho (Eds.), Manejo da salinidade na agricultura: Estudo básico e aplicados. Fortaleza, Ceará, Brasil: INCTSal.

Sangakkara, U. R. (1994). Response of selected tropical grasses to irrigation with brackish water. Pertanika Journal of Tropical Agricultural Science, 1721-21.

Santos, D. B., Voltolini, T. V., Azevedo, C. A. V., Nogueira, D. M., Silva, A. S. \& Medeiros, S. S. (2013). Tolerância do capim Marandu a salinidade. Embrapa Semiárido-Artigo em periódico indexado (ALICE).

Silva, J. L. D. A., Medeiros, J. F., Alves, S. S. V., Oliveira, F. A., Silva Junior, M. J. \& Nascimento, I. B. (2014). Uso de águas salinas como alternativa na irrigação e produção de forragem no semiárido nordestino. Revista Brasileira de Engenharia Agricola e Ambiental-Agriambi, 1866-72.

Soares Filho, W. S., Gheyi, H. R., Brito, M. E. B., Nobre, R. G., Fernandes, P. D. \& Miranda, R. S. (2016). Melhoramento genético e seleção de cultivares tolerantes à salinidade. In H. R. Gheyi, N. S. Dias, C. F. Lacerda \& E. Gomes Filho (Eds.), Manejo da salinidade na agricultura: Estudo básico e aplicados. Fortaleza, Ceará, Brasil.: INCTSal.

Sudene. 2017. Resolução $N^{o}$ 115/2017, 23 de novembro de 2017. Disponível em: http://sudene.gov.br/images/arquivos/conselhodeliberativo/resolucoes/resolucao115-23112017delimitacaodosemiarido.pdf. Acesso em 27 de janeiro de 2018.

Vale, M. B. \& Azevedo, P. V. (2013). Avaliação da produtividade e qualidade do capim elefante e do sorgo irrigados com água do lençol freático e do rejeito do dessalinizador. Holos, 3181-195.

Van Soest, P. J. (1994). Nutritional ecology of the ruminant (Vol. 1). Ithaca, NY, USA: Cornell University Press. 
Vieira, M. R., Lacerda, C. F., Cândido, M. J. D., Carvalho, P. L., Costa, R. N. T. \& Tabosa, J. N. (2005). Produtividade e qualidade da forragem de sorgo irrigado com águas salinas. Revista Brasileira de Engenharia Agrícola e Ambiental, 9(Supl.):42-46.

Recebido: 8 de fevereiro, 2019

Aprovado: 1 de março, 2019.

Publicado: 9 de abril, 2019.

Licenciamento: Este artigo é publicado na modalidade Acesso Aberto sob a licença Creative Commons Atribuição 4.0 (CC-BY 4.0), a qual permite uso irrestrito, distribuição, reprodução em qualquer meio, desde que o autor e a fonte sejam devidamente creditados 